\title{
STUDY SOME PHYSICAL PROPERTIES OF POL YMERIC BLENDS (SR/ PMMA)
}

Sihama I. Salih

Jawad K. Oleiwi

Hajir M. Ali

130005@uotechnology.edu.iq130041@uotechnology.edu.iq hajir_alqurashi@yahoo.com Materials Engineering Department, University of Technology, Baghdad, Iraq

\begin{abstract}
Many face organs are exposed to different environmental conditions in terms of different of ambient temperature, degradation, discoloration, changes in humidity and especially frequent washing of these organs. These conditions cause changes in the structure of materials so, for restoring the function and improving aesthetics of the affected areas of maxillofacial by surgical reconstruction and prosthetic rehabilitation the silicone rubbers (SR) and PMMA are the materials of choice. So that, the aim of this research is to investigate the effect of addition of polymethyl methacrylate (PMMA) material on the physical properties of blends from SR/PMMA at different weight percentage $(5 \%, 10 \%$, $15 \%$ and $20 \%$ ) of PMMA to silicone rubber. Fourier transform infrared spectrometer test ( FTIR), density, water absorption and thermal properties were done on the all prepared samples, which are used for maxillofacial prostheses applications. The results showed that there is good correlation in FTIR spectrum for reference silicone rubber and (SR/PMMA) polymer blend and this confer a good compatibility between silicone rubber matrix material and PMMA. As well as the physical properties showed that the favorite percent of PMMA is $10 \%$ which has ideal characteristic. So, this sample may be a suitable material to achieve the properties required for maxillofacial prosthetic applications.
\end{abstract}

KEYWORDS: Maxillofacial Prosthesis, Polymeric blends, Silicone rubber, PMMA, physical properties

دراسة بعض الخصائص الفيزيائية للخلائط البوليمرية (SR / PMMA)

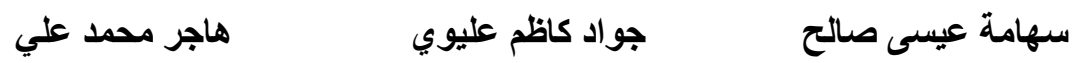

تتعرض العديد من أعضاء الوجه لظروف بيئية مختلفة من حيث اختلاف درجة الحر ارة المحيطة والرطوبة، التحلل،

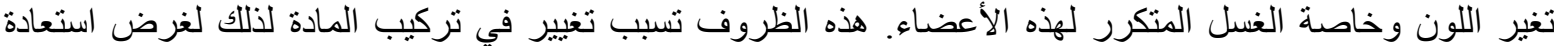

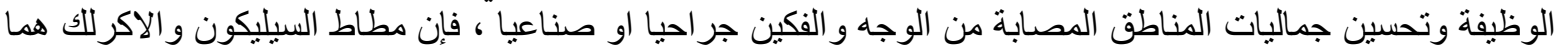

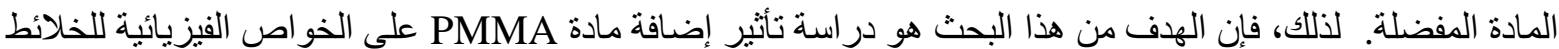

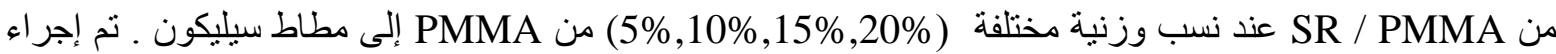
اختبار FTIR و الكثافة و امتصاصية الماء و الخصائص الحر ارية على جميع العينات المحضرة، و والتي تستخدم لتطبيقات الأطر اف الاصطناعية في الوجه و الفكين. وقد أظهرت النتائج أن هناك علاكية علاقة متقاربة في فحص السيليكون النقي والخليط البوليمري (SR / PMMA) وهذا يمنح نو افق جيد بين مالئ مادة الاساس مطاط السيليكون و PMMA كذلك أظهرت الخصائص الفيزيائية أن افضل نسبة المئوية من PMA هي مثالية. لذللك، قد تكون هذه العينة مادة واعدة لتحقيق الخصائص المطلوبة لتطبيقات الأطر اف الاصطناعية في الوجه 


\section{INTRODUCTION}

Maxillofacial defects caused by cancer or congenital diseases required high-quality prosthetic treatment and more comprehensive. The primary aim of the maxillofacial prosthodontics is to improve their self-respect, repair the patient's appearance and help them lead as normal a life as possible (Wiens JP et al., 2000 \& Jani RM et al., 1978). The ideal properties of a maxillofacial prosthesis are to be physically and mechanically similar to the replaced tissue, Capable of adhering to human tissue, Compatible with human tissue, both intrinsically and extrinsically coloring can be done. In 1960 Silicone elastomers were first used for external prosthesis (Deepthi V S, 2016). Due to the advantageous properties of Silicone elastomer such as low chemical reactivity, biocompatibility, optical transparency, and ease of manipulation, so that it's considering the most suitable material for facial prostheses (M. M. Hatamleh et al., 2010 \& Nouri Al-qenae, 2010 \& Colas A et al., 2005). PMA has a lack of methyl groups on the backbone carbon chain its long polymer chains are thinner and smoother and can slide past each other more easily. PMMA can be successfully utilized for specific types of facial defects, especially those in which little movement occurs in the tissue bed during function (e.g. fabrication of orbital prostheses) (W. D. Callister et al., 2010 \& Pfeiffer P. et al., 2004).

The using of silicone elastomers alone not possessing sufficient physical and mechanical properties with unsatisfactory strength, therefore many attempts were introduced to overcome these problems through the development of a new class of elastomer material, by polymer blends manufacturing which match some very important properties of two polymers along with diminishing their individual disadvantages (C. Koning, 1998). A polymer blend is define as type of materials in which two or more polymers are blended together to produce a new material with different physical properties. The properties of the blend are the best to those of the individual components (Askeland D.R et al., 2010).

Anna Karin Hulterstrom et al. (2008), studied the wettability, water sorption and solubility of silicone elastomers used for maxillofacial prostheses. Material that has absorbed water would show an increase in the wettability and surface free energy of the material. The results showed that condensation type polymers should no longer be used in prosthetic devices because it so large volumetric changes when exposed to liquid. While the addition type silicones showed little or no sorption and solubility. Marcela Filié Haddad et al. (2014), studied the effect of bonding techniques on bond strength between an acrylic resin and maxillofacial silicone elastomer which reinforced by two Nano particles. So that it shows a higher cohesion between acrylic resin and facial silicone. But after the aging period the ratio of failure of acrylic resinfacial silicone bond was increased.

Ebru D et al. (2015), described a technique to produces porous structure of the skin which is equally distributed and same-size pores for giving more natural appearance as human skin by used maxillofacial silicone elastomer.

Dhuha A. Shakir and Faiza M. Abdul-Ameer (2018), developed the mechanical properties of two types of maxillofacial silicone elastomers (VST50FRTV and Cosmesil M511 HTV) by added nano-TiO2. The results show that the incorporation of $(0.25 \%$ and $0.2 \%)$ nanofiller increased the tear strength, tensile strength, elongation percentage, and hardness of the materials.

Ahmed Nadher Jaber et al. (2018), Studied some mechanical properties of maxillofacial silicone elastomeric materials after added proper amount of polyester fiber by percent $(0 \%$, $0.25 \%, 0.5 \%$ and $0.75 \%$ ). The results show that mean value of mechanical properties for $0.25 \%$ by weight polyester fiber ( $2 \mathrm{~mm}$ length) reinforcement group increased significantly when compared to the other values of reinforcement groups which were gradually decreased. 
In this research the physical properties of different silicone maxillofacial materials evaluated. The most common cause for prefabrication of facial prosthesis is degradation in physical properties and color. The improvement of physical properties of polymer blend material (SR/PMMA) for applications of facial and maxillofacial prostheses was studied. The blends were characterization by the following density, water absorption, and thermal analysis.

\section{EXPERIMENTAL WORK:}

\section{Materials Used:}

In this research silicon rubber (SR); used as a matrix material, equipped from Shenzhen Hong Ye Jie Technology Co., LTD, type 630 RTV which is vulcanized at room temperature in condensation method. The properties are listed in Table (1) according to Supplier Company. It is generally consisting as a two part, one is a flowable liquid, and another is used as a catalyst material. Second material of polymer blend is a polymethyl methacrylate (PMMA) is cold curing resin type (Castavaria), provided from (Spofa Dental) Company. Table (2) shows some of the mechanical and physical properties of cold cure PMMA according to the supplied Company.

\section{Preparation Method:}

silicone rubber was firstly prepared as a neat sample (matrix) by mixing two parts of the silicone rubber, where part $\mathrm{A}$ as a base material and part $\mathrm{B}$ is catalyst material. The silicone crosslinking agent was added according to the manufacturer's recommended ratio of 10: 1 by weight (base: cross-linking agent) and mixed with the base material.

Secondly, preparation the binary polymeric blends samples (SR/PMMA) by mixing silicone rubber with PMMA polymer to loading level $(5 \%, 10 \%, 15 \%$ and $20 \%)$ of PMMA. Initially, a part $\mathrm{A}$ of silicone rubber in a liquid state is mixing with acrylic powder (PMMA) in standard proportion, and then silicone rubber catalyst (part B) mixed with liquid monomer (MMA), after that the two groups were mixed together well. Finally pouring the blend into the metallic mold and left them inside the mold at room temperature about (6 hrs.) according to the instructions of the supplier company, the material was allowed to polymerize at room temperature $(25 \pm 1 \circ \mathrm{C})$. After the polymerization curing completed, the specimens (as a plate) were carefully removed from the metallic molds, the testing samples were obtained by cutting the prepared plates according to the relevant ASTM standard for each test, and all properties were measured at room temperature $\left(25 \pm 1^{\circ} \mathrm{C}\right)$.

\section{Characterization and testing:}

Fourier transform infrared spectrometer (FTIR) test is performed according to (ASTM E1252) (Annual Book of ASTM Standard, 2002), made by (Bruker Optics Company, Germany), type is (TENSOR-27). FTIR was used to characterize the reference silicone rubber and binary polymeric blends samples (SR/PMMA). It is equipped with a room temperature DTGS detector, mid-IR source (4000 to 400) $\mathrm{cm}^{-1}$ and a $\mathrm{KBr}$ beam splitter. In order to evaluation the physical properties for all the prepared samples, all tests were performed in according to (ADA Specification No.12, 1999), where all the test specimens after preparation and polishing processes was stored in distilled water at $\left(37 \pm 1^{\circ} \mathrm{C}\right)$ for $48 \mathrm{hr}$.

For density tests, the samples were prepared according to ASTM standard (D-792) (Annual Book of ASTM Standard, 2006) and samples weights were measured according to Archimedes method by accurate balances kind: PS 360/C/1device. The specific gravity can be determined by the definition shown in equation (1) (Charles. E et al., 2008): 
Specific Gravity (S.G) $=\frac{w_{D}}{w_{D}-w_{i}+0.02}$

$W_{D}$ : Mass of dry sample (gm.).

Where:

$W_{i}$ : Mass of sample after immersing and suspended in water (gm).

0.02: Mass of practically immersed wire.

Specific gravity can be converted to density $\left(\mathrm{gm} / \mathrm{cm}^{3}\right)$ by multiplying the specific gravity by $D$ which represents the density of distilled water $\left(\mathrm{gm} / \mathrm{cm}^{3}\right)$ that equal to $(0.9975)$.

Water Absorption test is preformed according to (ASTM D570) (Annual Book of ASTM Standard, 2005). In this test, the samples were immersed in the distilled water at room temperature for $(24 \mathrm{hr})$, then samples were removed from distilled water and the surface was wiped off with a dry cloth and weighed by digital balance. The water absorption can be calculated according to the following equation (2):

Water Absorption $\%=\frac{w_{S}-w_{D}}{w_{D}} \times 100$

Where:

$W_{D}$ : Mass of dry sample before immersion

$W_{s}$ : Mass of sample after immersion in distilled water for $(24 \mathrm{hr})$ at room temperature.

For thermal analysis test, this test was performed according to apparatus manual of standard specifications instrument (Hot Disk Thermal Constants Analyzer, 2001). Thermal properties test was carried out by using thermal properties test device, manufactured by (Kelthley), type (Transient Plane Source (TPS) - 500). The hot disk sensor is placed between two pieces of the same sample material as Fig. 1, in order to avoid influence from outside boundaries of the sample; the sample should be larger than the sensor diameter to ensure stable values of both thermal conductivity and diffusivity. The values of thermal conductivity, thermal diffusivity and specific heat are read from the computerize gauge. The relationship between these properties is shown by the equation (3) (Donald V. Rosato et al., 2010 \& Jawad K. Oleiwi et al., 2018).

$\mathrm{D}_{\mathrm{th}}=\mathrm{K} /(\mathrm{Cp} . \rho)$

Where:

$\mathrm{D}_{\mathrm{th}}$ : Thermal diffusivity (mm2/s).

Cp: Specific heat (heat capacity) at constant pressure $\left(\mathrm{MJ} / \mathrm{m}^{3 \mathrm{o}} \mathrm{K}\right)$.

$\mathrm{K}$ : Thermal conductivity $\left(\mathrm{W} / \mathrm{m} .{ }^{\circ} \mathrm{K}\right)$.

$\rho$ : Mass Density (Bulk Density) $\left(\mathrm{kg} / \mathrm{m}^{3}\right)$.

\section{RESULTS AND DISCUSSIONS}

\section{FTIR spectrum:}

In order to full characterization for the bands of neat silicone rubber and the (SR/PMMA) polymer blends, Fourier Transform Infrared Spectrometer (FTIR) test was done. The FTIR a spectrum of reference silicone rubber in the range (400-4000 $\left.\mathrm{cm}^{-1}\right)$ is shown in Fig. 2; the spectrum is quite (Xishan Wen et al., 2017 \& Jun Feng et al., 2014). In general, the absorption peak at $2962.65 \mathrm{~cm}^{-1}$ is assigned to stretching vibration of $\mathrm{CH}_{3}$. The absorption peak at 1410 $\mathrm{cm}^{-1}$ is assigned to the rocking vibration of $-\mathrm{CH}_{2}$. The absorption peaks at $1258.52 \mathrm{~cm}^{-1}$ and $864.27 \mathrm{~cm}^{-1}$ are assigned to bending vibration and rocking vibration of $\mathrm{Si}-\mathrm{CH}_{3}$. The absorption peaks at $1080 \mathrm{~cm}^{-1}$ and $1009.28 \mathrm{~cm}^{-1}$ are assigned to the stretching vibration of Si-O-Si on 
backbone of silicone rubbers. The absorption peak at $787.39 \mathrm{~cm}^{-1}$ is assigned to the coupling of stretching vibration of $\mathrm{Si}-\mathrm{C}$ and rocking vibration of $-\mathrm{CH}_{3}$.

The FTIR spectra of polymers blend (SR: X\% PMMA) with different ratios of PMMA $(0,5$, 10, 15 and 20\%) are shown in Fig. 3. It can be seen from the infrared spectrum of these group of polymeric blend specimens; these spectra is quite similar to the FTIR spectrum of reference silicone rubbers which shown in Fig. 2, no other new peak or peak shifts were observed for the polymeric blends of SR/PMMA specimens with the addition of PMMA. This is due to the find physical bond and absence of any cross linking and chemical reaction between constituents of polymeric blends, as well as a there is no any new interaction in these specimens of polymeric blends.

\section{Density Property:}

The density of polymeric blends (SR: X\% PMMA) in different ratios (0, 5, 10, 15 and 20\%) of PMMA are show in Fig. 4. The polymeric blends of SR/PMMA specimens have the highest values of density as compare with the neat silicone rubbers, as well as, it can be noted from this figure that the density increases with increasing weight ratio of PMMA content in the blend and reach to the highest value $\left(1.119 \mathrm{~g} / \mathrm{cm}^{3}\right)$ at $10 \%$ ratio of PMMA, then start to decline with increasing the amount of PMMA, this is due to the adding of PMMA to silicone rubbers. Generally, SR matrix material is much weaker and leas density as compared to PMMA, moreover the addition of PMMA to SR with limited rates, it will be reduced the free volume such as spaces, gaps and pores in the prepared polymeric blend, which eventually leads to increased density of the prepared material. Based on the foregoing the addition of PMMA makes silicone rubbers to have highest density when mixed with PMMA at limited ratios. These materials it may be in good compatibility between them until to PMMA content reach up to $10 \%$ ratio, but when increased the PMMA ratio to larger than $10 \%$ this may be lead to the formation of heterogeneous structure as immiscible polymer blend and that lead to phases separation then disintegrations between these two materials with bad connecting between them. The high percent of PMMA resulting agglomerate (uneven distribution) in area than others with high void spaces, the greater void contents at the interface between the components of the polymer blends cause low density (Das et al., 2016 \& Sihama Issa Salih et al., 2017).

\section{Water absorption test:}

From Fig. 5 which shown the relation between water absorption as function of PMMA content in the blend, it was found that this property increased with increased PMMA percent. Neat silicone rubber specimen have the lower value of water absorption that equal $(0.0597 \%)$, while polymeric blend specimens with $20 \%$ PMMA have higher value that reach $(0.7152 \%)$. Most elastomeric polymers such as silicon rubber are hydrophobic in the macro sense (Mohammad Amin et al., 2017), meaning they do not absorb water. Such materials are all considered to be closed cell. So, the increased of the water absorption of SR when adding PMMA to its, may be due to the partial replacement of the hydrophobic silicon rubber resin by PMMA which have hydrophilic properties (Sihama E. Salih et al., 2016). As well as the nature of bonding at the interfacial region between SR and PMMA materials, may be leads to increase the micro voids and open spaces (open poreses) in the polymer blends (SR/PMMA) materials, therefore these reasons lead to increasing of the water absorption of (SR/PMMA) polymeric blends (Zubeda Begum et al., 2011, Tariq Aziza et al., 2003).

\section{Thermo-physical properties}

The thermo-physical properties (thermal conductivity, thermal diffusivity and volumetric specific heat) values of the neat silicone rubber specimen and polymeric blend specimen are illustrated in Figs. 6-7-8 respectively. 
These figures illustrate the effect of the addition of PMMA to silicone rubber on the thermophysical properties for polymeric blends (SR/PMMA) specimens. It can be noted from these figures that the decreases of both thermal conductivity and thermal diffusivity while volumetric specific heat increases with an increase in the ratio of PMMA content in the polymeric blends, as compared with neat silicone rubber specimen. It is known that heat flows within the insulation material by the transmission of phonons (thermal carrier) and free electrons (if present). Both of these carriers have a certain mean free path between collisions and an average velocity. The phonons velocity is high in light and in stiff materials. The mean free path of a phonon is structure sensitive and can be large in pure specimens of high perfection. Polymers have no electrons and low stiffness (low phonon velocity), so these polymers have low conductivities. The decreasing in thermal conductivity of polymeric blend was caused by the presence of PMMA material. The conductivity of a polymeric blend is affected by the interface adhesion between constituents of polymeric blends, since the conductivity may be impaired by the presence of an interfacial layer of some sort, or by voids or cracks in the vicinity of the interface. According to the results obtained these polymeric blends can be classified as materials have low thermal conductivity behavior as compared with neat silicone rubber.

Since the PMMA is thermal insulating material and have the bulky pendent groups on the polymer repeating unit of PMMA which are $(\mathrm{CH} 3)$ and $(\mathrm{COOCH} 3)$ induce several interesting properties. Crystallization is blocked by the pendent groups because the molecules cannot get close to form crystalline bonds. This causes PMMA to be amorphous (Sihama Issa Salih et al., 2017). Pendent groups snag on adjacent groups nearly eliminating slip between polymer chains. So, the thermal conductivity and thermal diffusion values decrease when the ratio of the added PMMA is increased, due to the irregularity structural of PMMA material. So, the polymeric blend (SR/PMMA) has a random heterogeneous structure. This leads to increase the dispersal of thermal energy and this in turn will lead to a decrease in thermal conductivity and thermal diffusion of the prepared polymeric blends material. Figure 8 shows that the value of the volumetric specific heat increases as the PMMA content in blend increases, this associated to the volumetric specific heat which is inversely proportional to the thermal conductivity and thermal diffusion, moreover, the thermal diffusion is dependent on the density of the material, when the density of the material is increased (as shown in Fig. 4), conversely to that the thermal diffusivity of the material it will decreased this results are in a good agreement with other workers results (Sihama Issa Salih et al., 2018, Jawad K. Oleiwi et al., 2018).

\section{CONCLUSIONS}

It was concluded from the test results of the prepared polymeric blends (SR/PMMA) that:

1. there is good correlation in FTIR spectrum for reference silicone rubber and (SR/PMMA) polymer blend and this confer a good compatibility between silicone rubber matrix material and PMMA, where there are no other new peaks or a deviation in the positions of peak were observed for the polymeric blends of SR/PMMA specimens with the addition of PMMA.

2. The density of (SR/PMMA) polymer blend increased and reaches to the highest values at $10 \%$ ratio of PMMA in blend, as well as the water absorption increased with the addition of PMMA to the blend.

3. The thermal conductivity and thermal diffusivity values decrease when PMMA added to silicone rubber, due to the irregularity structural of PMMA material. So, this sample may be a suitable material to achieve the properties required for maxillofacial prosthetic applications. 
Table 1: shows Properties of Silicon Rubber according to Supplier Company.

\begin{tabular}{cc}
\hline Model & $\mathbf{6 3 0}$ \\
\hline Color & White. \\
Mixing ratio (\%) & $2-3$ \\
Curing time (hrs., under $\left.25^{\circ} \mathrm{C}\right)$ & $4-5$ \\
Hardness ( Shore A ) & $30 \pm 2$ \\
Tensile strength (MPa) & $4.3+1 /-0.5$ \\
Tear strength (kN/m & $26+5 /-2$ \\
Viscosity (After A/B mixed ,mPa.s) & $27000+5000 /-8000$ \\
Shrinkage rate $(\%)$ & $\leq 0.3 \%$ \\
Elongation $(\%)$ & $\geq 400$ \\
\hline
\end{tabular}

Table 2: shows the properties of neat PMMA according to the supplied Company.

\begin{tabular}{cc}
\hline Property & Value \\
\hline Brinell hardness & $\min .120 \mathrm{Mpa}$. \\
Bending strength & $\min .65 .5 \mathrm{Mpa}$. \\
Setting time & Max. $7 \mathrm{~min}$. \\
Time of solubility & Max. $4 \mathrm{~min}$. \\
Time required to prepare nontacky plastic & $4-6 \mathrm{~min}$. \\
mixture & \\
Resistance to impact & $\min .0 .40 \mathrm{~J} / \mathrm{cm}^{2}$ \\
Absorbability & Max. $32 \mathrm{mg} / \mathrm{mm}^{3}$ \\
Solubility & Max. $8 \mathrm{mg} / \mathrm{mm}^{3}$ \\
\hline
\end{tabular}

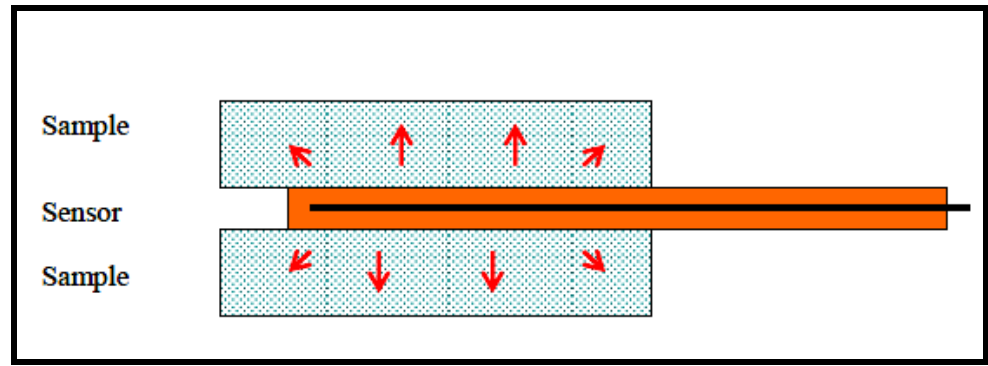

Fig. 1: Hot Disk sensor operation. 


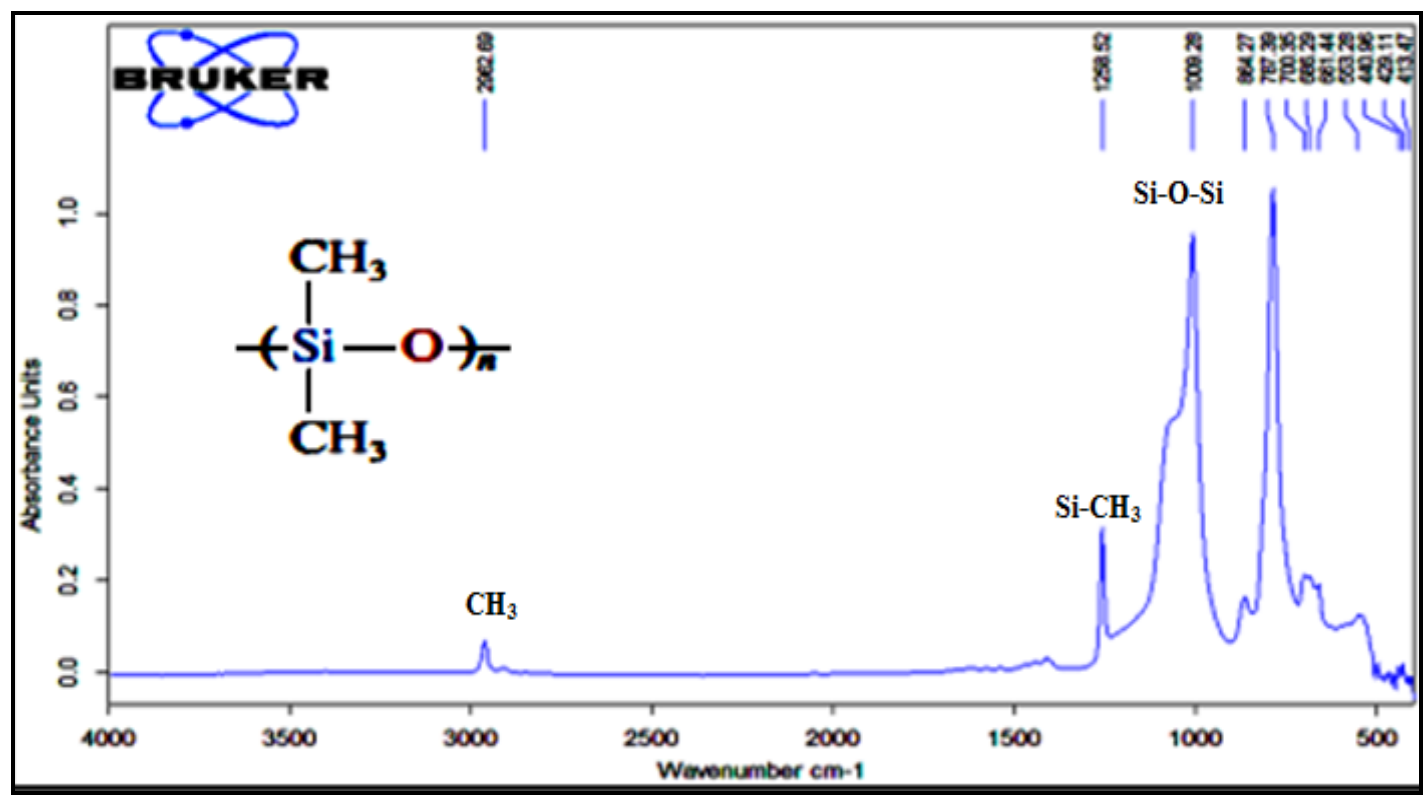

Fig. 2: Shows FTIR spectrum for neat silicone rubber material.

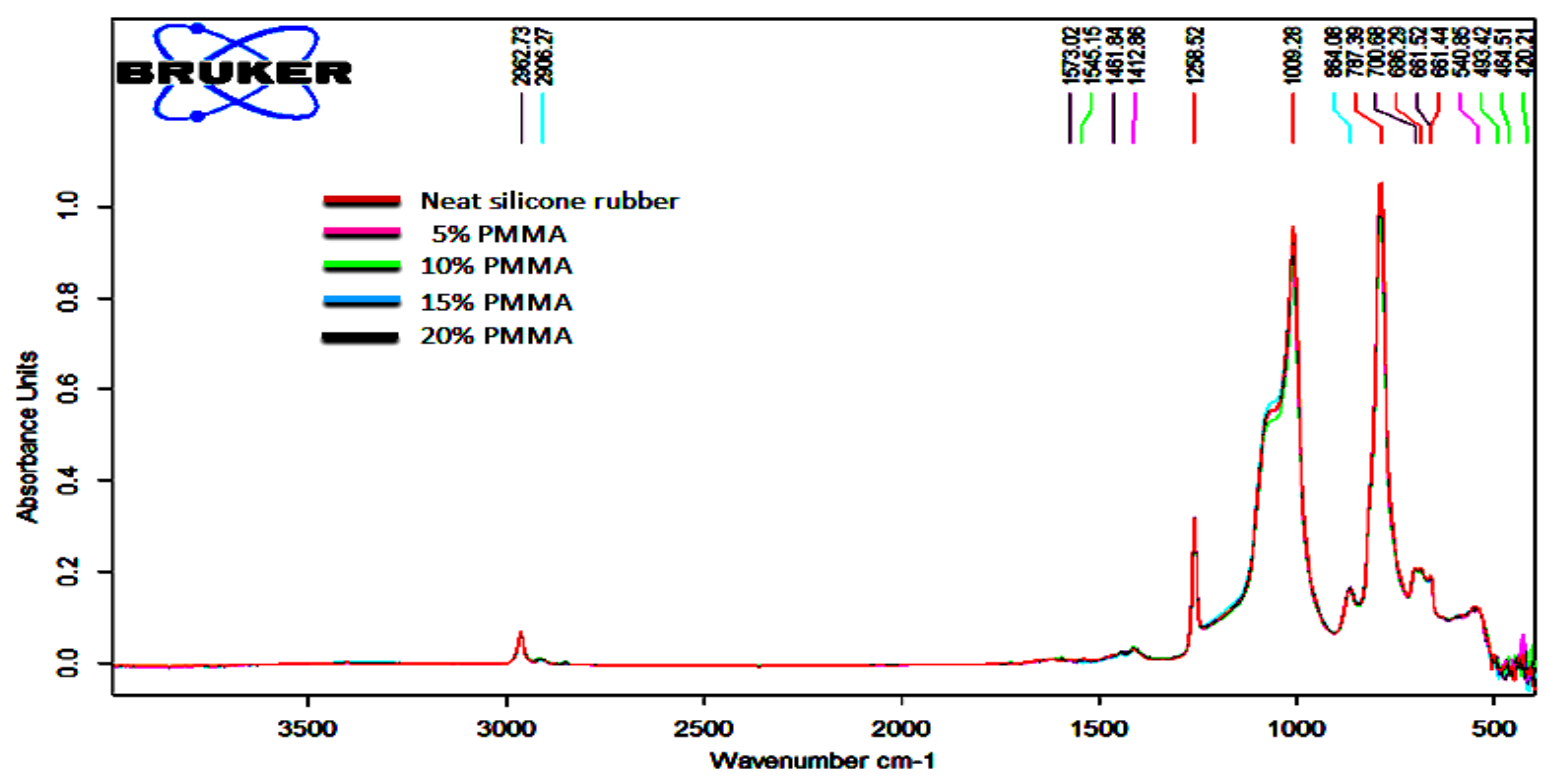

Fig. 3: Shows FTIR spectra of reference silicone rubber and (SR/PMMA) polymer blend as a function of PMMA content in blend. 


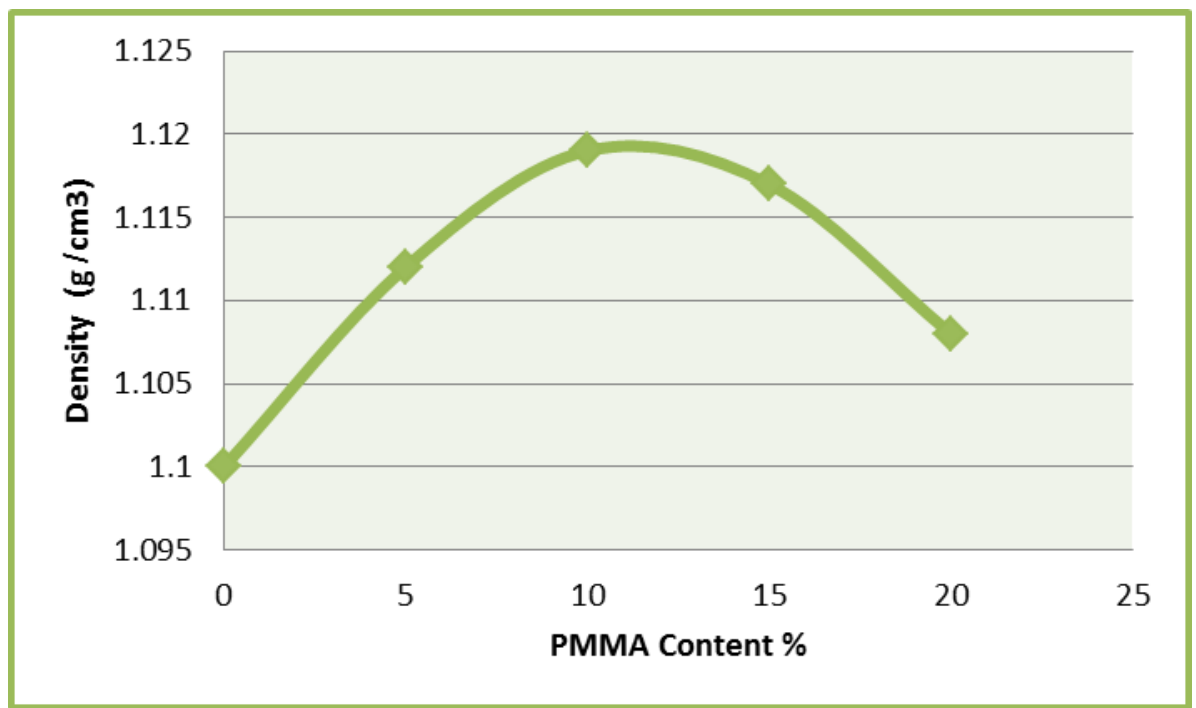

Fig. 4: Shows the density of SR/PMMA polymeric blends as a function of PMMA content in blend

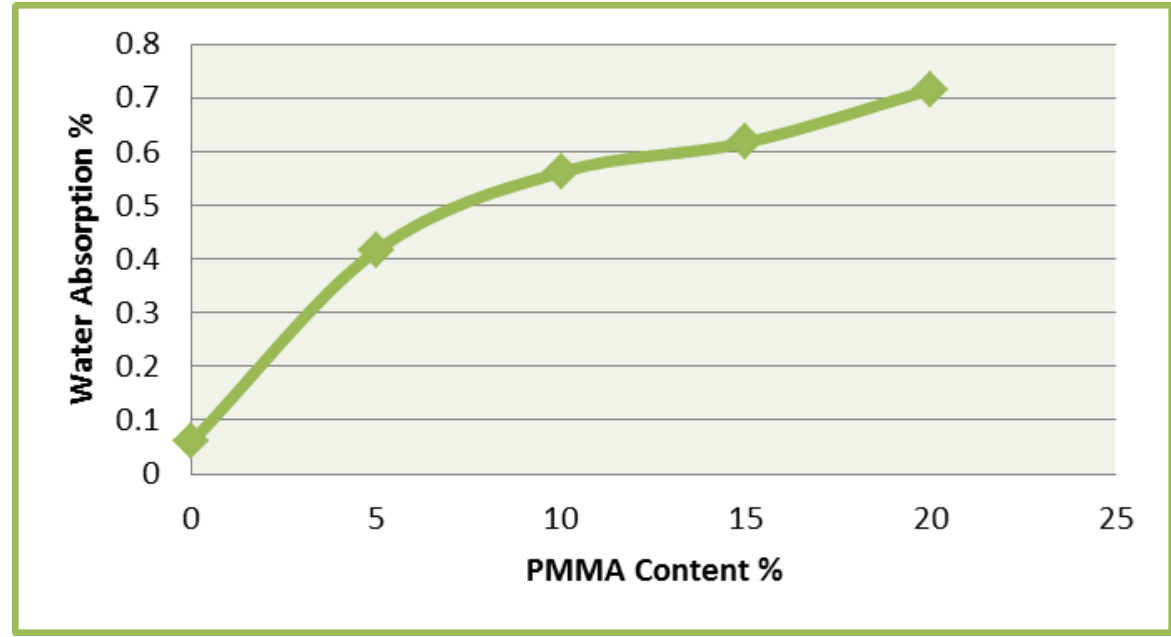

Fig. 5: Water absorption property of SR/PMMA polymeric blends as a function of PMMA content in blend

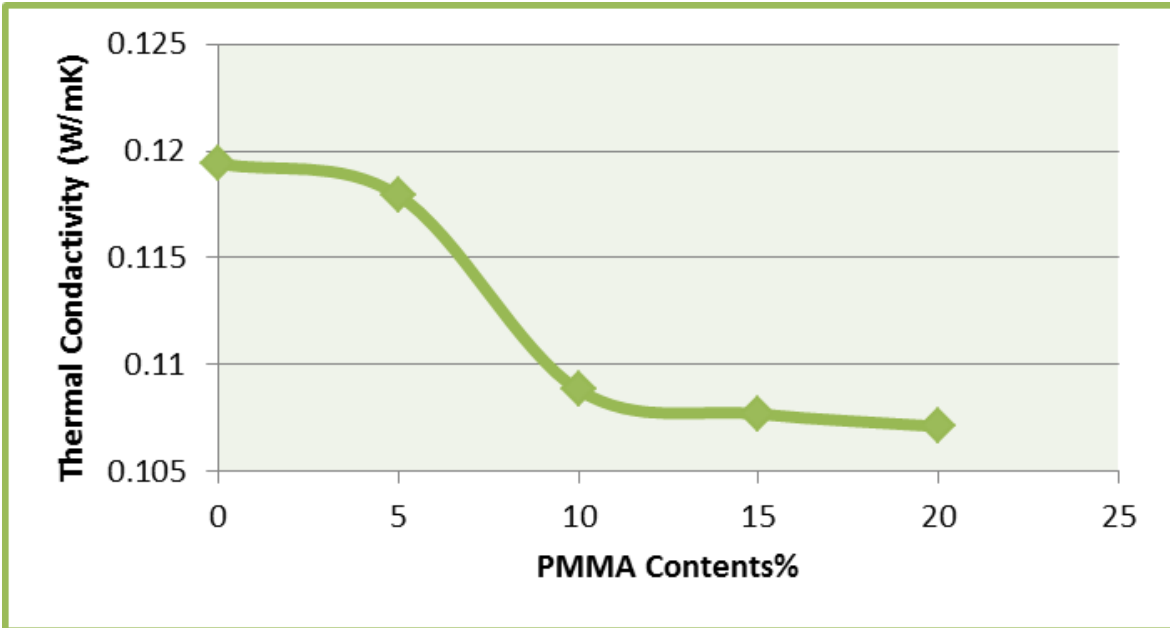

Fig. 6: The thermal conductivity of SR/PMMA polymeric blends as a function of PMMA content in blend 


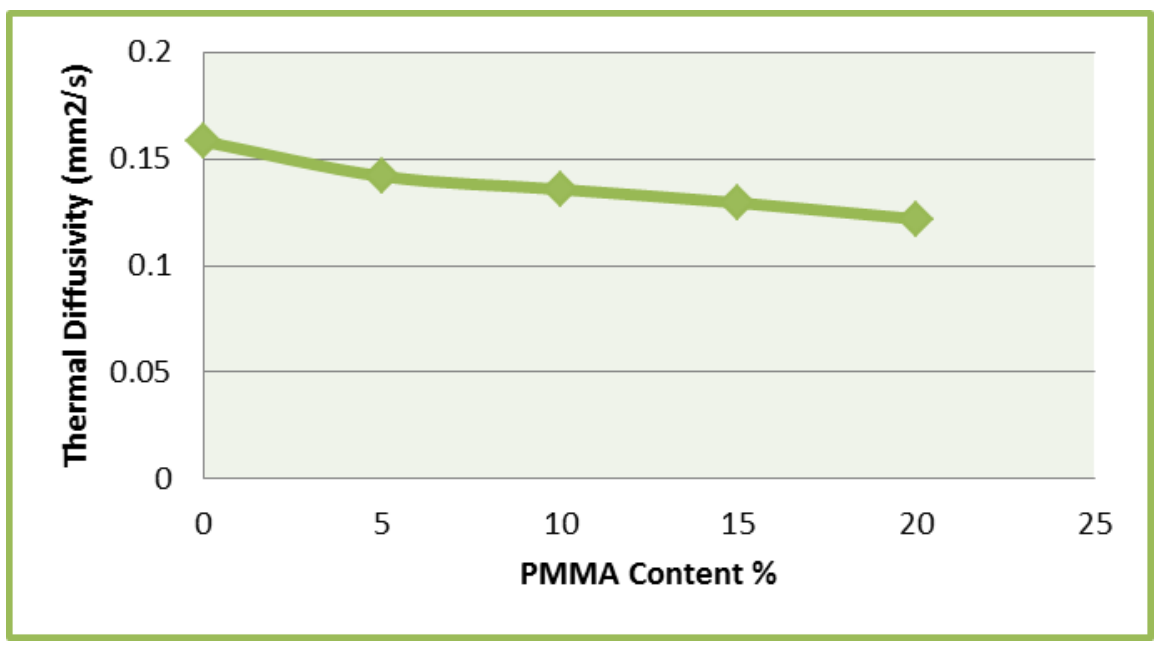

Fig. 7: The thermal diffusivity of SR/PMMA polymeric blends as a function of PMMA content in blend

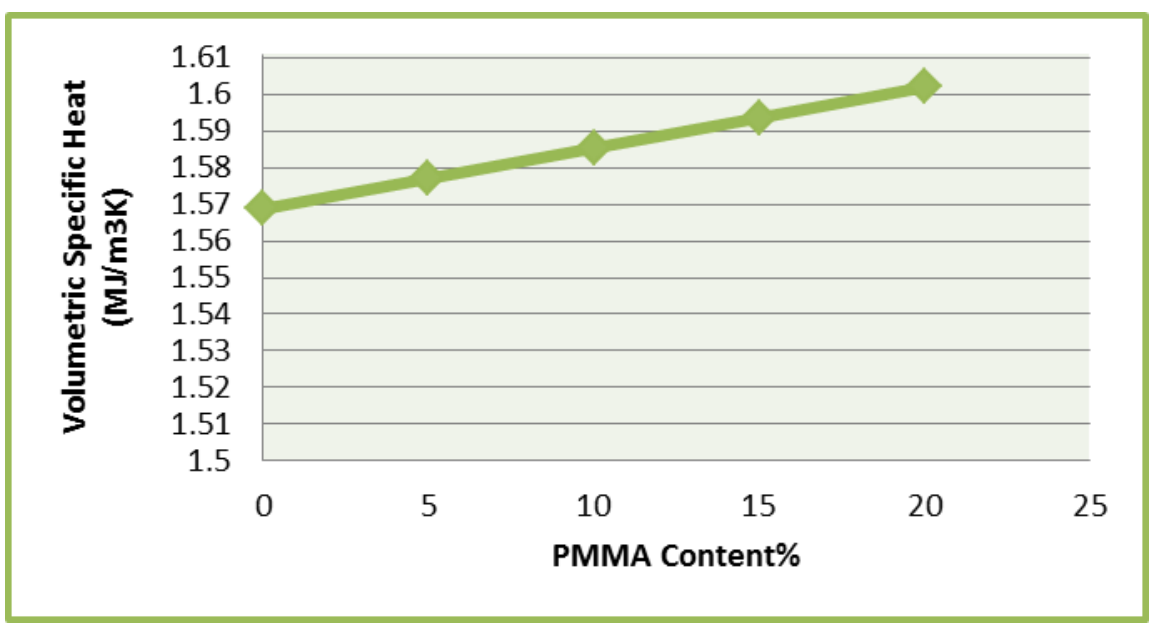

Fig. 8: The volumetric specific heat of SR/PMMA polymeric blends as a function of PMMA content in blend

\section{REFERENCES}

Anna Karin Hulterstrom, Anders Berglund and I. Eystein Ruyter, "Wettability, water sorption and water solubility of seven silicone elastomers used for maxillofacial prostheses", J Mater Sci: Mater Med, DOI 10.1007/s10856-006-0027-8, (2008) 19:225231.

Andres CJ, Haug SP, Brown DT, Bernal G., "Effects of environmental factors on maxillofacial elastomers" (Pt 2). Report of survey. J Prosthet Dent, (1992), 68(3):519-22.

Annual Book of ASTM Standard,"Standard Practice for General techniques for Obtaining Infrared Spectra for Qualitative Analysis", (2002) E 1252-98, PP 1-11.

Annual Book of ASTM Standard, "Standard Test Method for Density and Specific Gravity (Relative Density) of Plastics by Displacement Methods", D 792, (2006) Vol. (09.01), PP. (1-5). 
Annual Book of ASTM Standard,"Standard Test Method for Water Absorption of Plastics", D 570-98, (2005) Vol.08.81, pp. (1-3).

Askeland D.R. Pradeep P. Fulay,"Essential of materials science and Engineering" (2nd end), (2010) New York, USA.

C.Koning, M. V. Duin, Ch.Paagnoulle, R.Jerome, "Strategies for compatibilization of polymer blends", Prog. Polym. Sci.,(1998), Vol. 23, pp.707 - 757.

Charles. E. Carraher and Jr. Seymour Carraher's, "Polymer Chemistry", Seventh Edition by Taylor \& Francis Group, (2008) LLC.

Colas A and Curtis J. "Silicone Biomaterials: History and Chemistry in Biomaterials Science: An Introduction to Materials in Medicine", 2nd ed., (2005) Academic Press: 8086.

Das, Geetanjali, and Sandhayarani Biswas, "Physical, Mechanical and Water Absorption Behavior of Coir Fiber Reinforced Epoxy Composites Filled With A12O3 Particulates", Materials Science and Engineering, (2016) Vol.115, No.1, PP.(012012), IOP Publishing.

Deepthi V S, "Maxillofacial Prosthetic Materials", Journal of International Medicine and Dentistry, (2016) 3(1): 02-11.

Donald V. Rosato, Marlene G. Rosato and Nick R. Schott, "Plastics Technology Hand Book", Momentum Press, LLC Taiwan, (2010) Vol.1.

Ebru D. Cifter, Meltem Ozdemir-Karatas, Erkan Sancakli, and Ali Balik, "A surface roughening technique for maxillofacial prostheses", the journal of prosthetic dentistry, (2015) Vol. 113, Issue 3, March,.

"Hot Disk Thermal Constants Analyzer", Instruction Manual, Canada, (2001).

Jani RM, Schaaf NG., "An evaluation of facial prostheses. J Prosthet Dent", (1978) 39(5):546-50.

Jawad K. Oleiwi, Sihama I. Salih \& Hwazen S. Fadhil, "Water Absorption and Thermal Properties of PMMA Reinforced by Natural Fibers for Denture Applications", International Journal of Mechanical and Production Engineering Research and Development (IJMPERD), (2018) Vol. 8, Issue 3, Jun, PP 1105-1116.

Jun Feng, Qinglian Zhang, Zhengkai Tu, Wenmao Tu, Zhongmin Wanc, Mu Pan, Haining Zhang, "Degradation of silicone rubbers with different hardness in various aqueous solutions" Polymer Degradation and Stability, (2014) 109, 122-128.

M. M. Hatamleh and D. C. Watts, "Effects of accelerated artificial daylight aging on bending strength and bonding of glass fibers in fiber-embedded maxillofacial silicone prostheses," Journal of Prosthodontics, (2010) vol. 19, no. 5, pp. 357-363. 
Marcela Filié Haddad, Marcelo Coelho Goiato, Daniela Micheline dos Santos, Aldiéris Alves Pesqueira, Amália Moreno, Lucas Zago Naves and Mariana Vilela Sonego, Bonding of facial silicon with nanoparticles to an acrylic resin substrate", International Journal of Adhesion \& Adhesives (2014) 54, 206-213.

Mohammad Amin, Mohammad Akbar and Salman Amin, "Hydrphbicity of Silicone Rubber Used for Outdoor Insulation (An Overview)", Rev. Adv. Mater. Sci. (2017)Vol. 16(2007), PP 10-26.

Nouri Al-qenae, "Nano ceramic fiber Reinforced Silicone Maxillofacial Prosthesis", Dentistry, Indiana University, (2010) Thesis M.Sc.

Pfeiffer P. and Rosenbauer E. U., "Residual Methyl Methacrylate Monomer, Water Sorption and Water Solubility of Hypoallergenic Denture", Journal Pros. Dent., (2004) Vol. 92, PP. 72-78.

Sihama Issa Salih, Wleed Bdaiwi Salih, Salam Obaid Abdulghani, "Investigation of Physical Properties of Polymeric Nanocomposite Material Used in Structural Applications", Diyalas Journal for Pure Sciences, (2017) Vol: 13 No:1 , January PP 60-71.

Sihama E. Salih, Jawad K. Oleiwi, Alaa Mohammed.T, "Effect of Water Absorption on the Compressive Strength for PMMA Nano Composites and PMMA Hybrids Nano Composites Reinforced by Different Nanoparticles Used in Dental Applications", Eng. \& Tech. Journal, (2016) Vol. 34, No. 14, PP 2654-2669.

Sihama Issa Salih, Wleed Bdaiwi Salih, Husam Sakin Hamad,"Preparation and characterization of thermo-physical properties of polymer hybrid nanocomposite of Unsaturated Polyester Resin”, Iraqi Journal of Physics, (2018) Vol.16, No.37, PP. 136-148.

Tariq Aziza, Mark Watersa and Robert Jagger,"Analysis of the properties of silicone rubber maxillofacial prosthetic materials", Journal of Dentistry 31, 67-74, 2003.

Wiens JP and Wiens RL, "clinical maxillofacial prosthetics", Psychological management of the maxillofacial prosthetic patient in Taylor TD, ed,. Quintessence Publishing Co., (2000) Inc.: Chicago, IL.

W. D. Callister and D. G. Rethwisch, "Materials Science and Engineering", 8th ed., John Wiley and Sons. Inc., (2010) New York,USA .

Xishan Wen, Xiaoqing Yuan, Lei Lan, Lu Hao, Yu Wang, Shaodong Li , Hailiang Lu1, ID and Zhenghong Bao, "RTV Silicone Rubber Degradation Induced by Temperature Cycling" Energies, (2017) 10, pp1054-1066.

Zubeda Begum, Mohammed Zaheer Kola, Paran Joshi, "Analysis of the properties of commercially available silicone elastomers for maxillofacial prostheses", Journal of Contemporary Dentistry, AUGUST (2011),2(4). 